\title{
Commercial Synthesis of BMS-663068
}

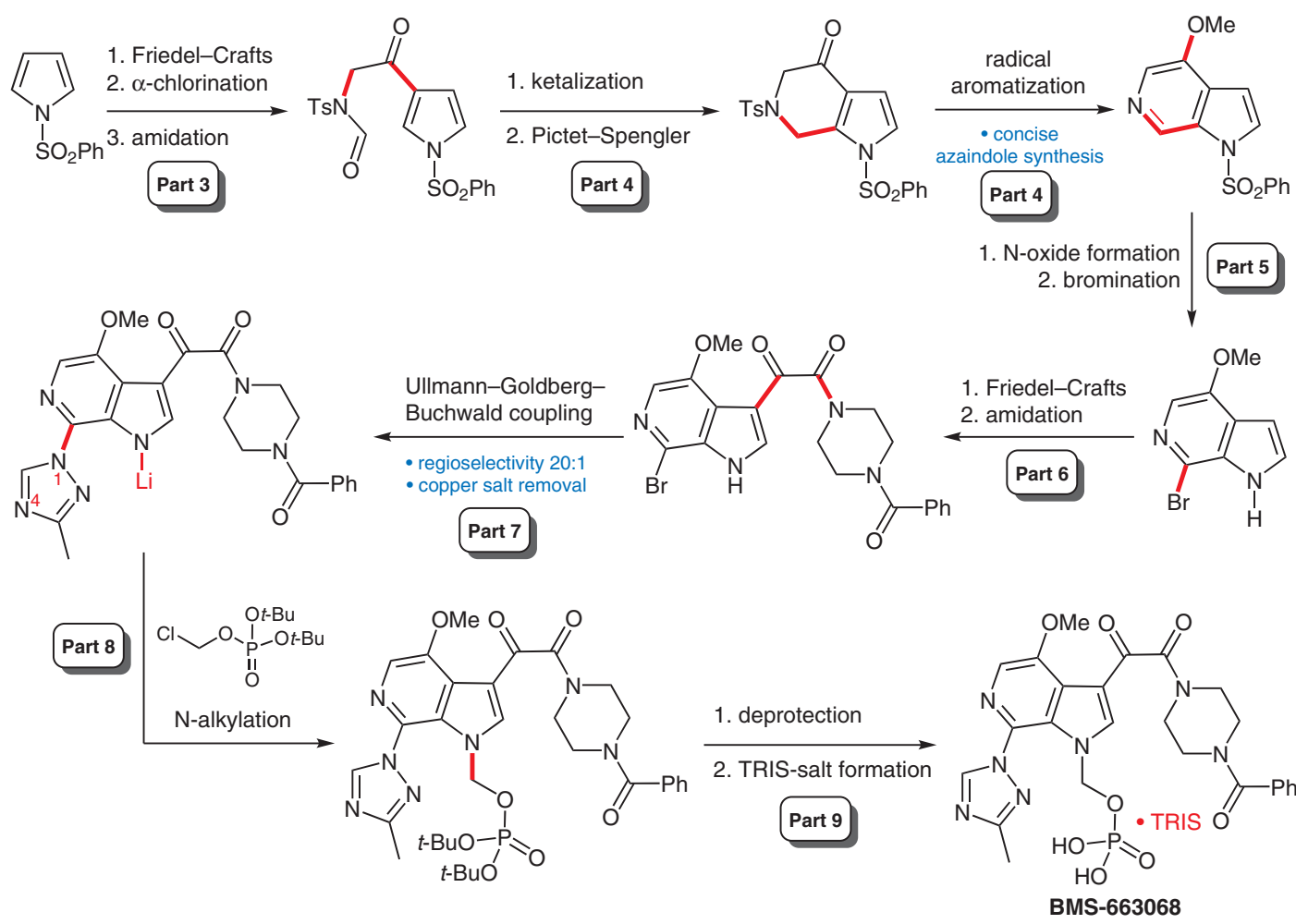

Preparation of HIV Attachment Inhibitor BMS-663068

Part 1. Evolution and Enabling Strategies. DOI: 10.1021/acs.oprd.7b00134

Part 2. Strategic Selections in the Transition from an Enabling Route to a Commercial Synthesis. DOI 10.1021/acs.oprd.7b00121

Part 3. Mechanistic Studies Enable a Scale-Independent Friedel-Crafts Acylation. DOI: 10.1021/acs.oprd.7b00115

Part 4. Synthesis of the 6-Azaindole Core. DOI: 10.1021/acs.oprd.7b00152

Part 5. Selective C-7 Bromination of the 6-Azaindole Core. DOI: 10.1021/acs.oprd.7b00132

Part 6. Friedel-Crafts Acylation/Hydrolysis and Amidation. DOI: 10.1021/acs.oprd.7b00133

Part 7. Development of a Regioselective Ullmann-Goldberg-Buchwald Reaction. DOI: 10.1021/acs.oprd.7b00191

Part 8. Installation of the Phosphonoxymethyl Prodrug Moiety. DOI: 10.1021/acs.oprd.7b00135

Part 9. Active Pharmaceutical Ingredient Process Development and Powder Properties. DOI: 10.1021/acs.oprd.7b00138

Significance: The entire issue 8 of Organic Process Research \& Development is devoted to an extraordinarily detailed account of the development of a commercial synthesis of the HIV attachment inhibitor BMS-663068 by workers at BristolMyers Squibb. The strategy, tactics and mechanistic illumination that transformed enabling routes to a commercial process that delivered $>1000 \mathrm{~kg}$ of $\mathrm{API}$ are presented in nine back-to-back papers.
Comment: By way of an overture, Yan and Baran provide a graphical synopsis of the synthesis (see Scheme), innovations and key achievements. Every atom of BMS-663068 is derived from economical, readily available, safe, and easily handled compounds, thereby ensuring a robust and secure supply chain for all raw materials. Moreover, the synthesis is noteworthy for being free of challenging reaction conditions.

\section{Key words}

BMS-663068

HIV attachment inhibitor

scalable synthesis 